\title{
Management of osteoporosis with calcitriol in elderly Chinese patients: a systematic review
}

REVIEW

Clinical Interventions in Aging

28 March 2014

Number of times this article has been viewed

Ruo-xi Liao

Miao Yu

Yan Jiang

Weibo Xia

Department of Endocrinology, Key Laboratory of Endocrinology, Ministry of Health, Peking Union Medical College Hospital, and Chinese Academy of Medical Sciences, Beijing, People's Republic of China

Video abstract

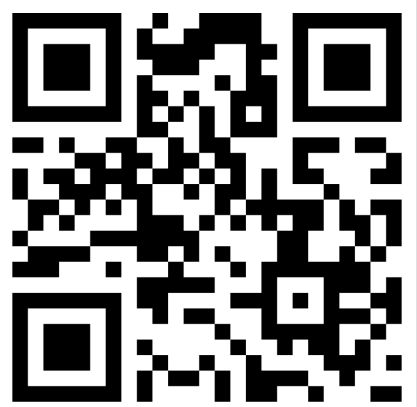

Point your SmartPhone at the code above. If you have a QR code reader the video abstract will appear. Or use: http://dvpr.es//cn32p8
Correspondence: Weibo Xia Department of Endocrinology, Key Laboratory of Endocrinology, Ministry of Health, Peking Union Medical College Hospital, Chinese Academy of Medical Sciences, Dongdansantiao Street, Beijing 100730, People's Republic of China Email xiaweibo@medmail.com.cn
Abstract: Osteoporosis, a skeletal disorder characterized by a reduction in bone strength, is becoming a major public health problem in the People's Republic of China, with a rapid increase observed among the population. Chinese guidelines particularly recommend use of active vitamin $\mathrm{D}$ in managing osteoporosis. $1,25-(\mathrm{OH})_{2} \mathrm{D}_{3}$ (calcitriol) is an active vitamin $\mathrm{D}$ metabolite. It plays a role in many biological processes, especially in bone metabolism and muscle function, and is mediated by vitamin D receptors. Osteoporosis in elderly men and women is characterized by uncoupled bone remodeling, which is induced by sex hormone deficiencies, somatopause, vitamin D deficiency, reduced synthesis of D hormone, and lack of receptors or receptor affinity for D hormone in target organs. Reviewed here are six randomized controlled trials on calcitriol monotherapy and five on calcitriol therapy combined with other antiosteoporotic agents. Evidence from these trials shows that calcitriol monotherapy can improve bone mineral density in elderly osteoporotic Chinese patients but may be insufficient for long-term treatment. Calcitriol can also decrease bone turnover markers and bring about significant improvements in muscle strength. Further, calcitriol in combination with other therapeutic bone agents was shown to be well tolerated and capable of additional bone-preserving effects compared with use of calcitriol alone in areas including bone mineral density, bone turnover markers, bone pain improvement, and fracture incidence. Hypercalcemia and hypercalciuria, the most common side effects of calcitriol therapy, were not documented in the trials reviewed, and might have been the result of the low dosages used. One study showed that treatment with calcitriol can improve quality of life in patients with osteoporosis, although not to the same extent as bisphosphonates.

Keywords: osteoporosis, vitamin D, calcitriol, vitamin D receptor, review

\section{Introduction}

Osteoporosis is a skeletal disorder characterized by diminished bone strength that can result in an increased risk of fracture. In 2006, among the segment of the Chinese population aged 50 years or older, 65 million people were considered to be osteoporotic, while an additional 213 million were estimated to have osteopenia. ${ }^{1}$ Also, a recent study revealed a rapid increase in the incidence of hip fractures in the Beijing area. $^{2}$ In light of these severe public health challenges, the prevention and treatment of osteoporosis is of great importance in the People's Republic of China. The Chinese guidelines for diagnosis and management of osteoporosis ${ }^{3}$ recommend both lifestyle intervention and medical treatment to prevent osteoporotic fractures. Calcium and vitamin D supplements are the essential steps that should be taken prior to embarking on medication. Based on the published evidence, bisphosphonates, calcitonin, hormonal replacement therapy, selective estrogen receptor modulators, strontium, 
and parathyroid hormone are all recommended in the guidelines. According to the guidelines, ${ }^{3}$ active vitamin $\mathrm{D}$ is recommended for osteoporotic patients who are elderly, have renal dysfunction, or have $1 \alpha$-hydroxylase deficiency. Active vitamin $\mathrm{D}$ includes $1 \alpha$-hydroxyvitamin $\mathrm{D}(1 \alpha$-calcidol) and 1,25-dihydroxyvitamin D (calcitriol). The latter, first approved for the treatment of osteoporosis by the China State Food and Drug Administration in 1992, is still widely used as an intervention for osteoporosis in the People's Republic of China. It is thus necessary to clarify the evidence surrounding the use of active vitamin D, in particularly calcitriol, in the Chinese population with osteoporosis.

\section{Physiological and pharmacological effects of calcitriol}

$1,25(\mathrm{OH})_{2} \mathrm{D}_{3}$ is an active vitamin $\mathrm{D}$ metabolite. It is converted from $25-\mathrm{OH}-\mathrm{D}_{3}$ by hydroxylase. Mediated by the vitamin $\mathrm{D}$ receptor (VDR), $1,25(\mathrm{OH})_{2} \mathrm{D}_{3}$ plays an important role in many biological processes, including bone metabolism, muscle function, and the immune response. Although recent attention has been focused on the nonskeletal effects of vitamin $\mathrm{D}$, it is well established that vitamin $\mathrm{D}$ is critical for bone metabolism.

It is uncertain whether $1,25(\mathrm{OH})_{2} \mathrm{D}_{3}$ acts directly on bone or if it mediates its antirachitic effects indirectly by stimulation of intestinal absorption of calcium and phosphorus. Some studies have shown that differentiation of osteoblasts and osteoclastogenesis can be stimulated by $1,25(\mathrm{OH})_{2} \mathrm{D}_{3} \cdot{ }^{4}$ The effect of $1,25(\mathrm{OH})_{2} \mathrm{D}_{3}$ on osteoclastogenesis is indirect, which requires cell-to-cell contact between osteoblasts and osteoclast precursors. When recognized by its receptor on osteoblasts, $1,25(\mathrm{OH})_{2} \mathrm{D}_{3}$ can increase expression of receptor activator of NFKB ligand (RANKL), which binds RANK. RANK on the preosteoclast induces the preosteoclast to become a mature osteoclast. ${ }^{5} 1,25(\mathrm{OH})_{2} \mathrm{D}_{3}$ has also been reported to stimulate production of calcium-binding proteins, ie, osteocalcin and osteopontin, in osteoblasts. Runx2, a transcriptional regulator of osteoblast differentiation, is also regulated by $1,25(\mathrm{OH})_{2} \mathrm{D}_{3} \cdot{ }^{4}$ Transgenic mice overexpressing the VDR in osteoblastic cells show increased bone formation, which further indicates the direct effects of $1,25(\mathrm{OH})_{2} \mathrm{D}_{3}$ on bone. ${ }^{6}$ At the same time, from a physiological perspective, vitamin $\mathrm{D}$ can influence bone metabolism by providing calcium and phosphate through its effects on the gut, bone, and kidneys. $1,25(\mathrm{OH})_{2} \mathrm{D}_{3}$ interacts with its specific nuclear VDR in the intestines to enhance the efficiency of intestinal absorption of calcium and phosphorus. In the kidneys, it affects calcium transport in the distal tubule by enhancing the action of parathyroid hormone and by inducing transient receptor potential cation channel, subfamily V, member 5 and calbindins. Another important effect of $1,25(\mathrm{OH})_{2} \mathrm{D}_{3}$ in the kidneys is inhibition of cytochrome P450 (CYP)27B1 (25-OH-D $1 \alpha$-hydroxylase) and induction of CYP24 (1,25-(OH) $)_{2}-\mathrm{D}_{3}$ 24-hydroxylase). ${ }^{7}$ Effects of $1,25(\mathrm{OH})_{2} \mathrm{D}_{3}$ on reabsorption of sodium phosphate transporter b-mediated phosphate in the proximal tubule have also been suggested. ${ }^{8}$ Depending on parathyroid hormone status and on experimental conditions, $1,25(\mathrm{OH})_{2} \mathrm{D}_{3}$ has been reported to increase or decrease renal reabsorption of phosphate. ${ }^{6}$

The effects of vitamin D on muscle function were first shown by Birge and Haddad..$^{9}$ There are three ways in which vitamin D metabolites can affect muscle metabolism. ${ }^{10}$ First, a VDR in skeletal muscle cells that specifically binds $1,25(\mathrm{OH})_{2} \mathrm{D}_{3}$ can lead to a ligand-receptor interaction that results in a final transcription complex. This genomic pathway was found to influence muscle cell calcium uptake, phosphate transport across the muscle cell membrane, and phospholipid metabolism, as well as to mediate cell proliferation and subsequent differentiation into mature muscle fibers. ${ }^{11}$ Second, there is evidence indicating that $1,25(\mathrm{OH})_{2} \mathrm{D}_{3}$, possibly through a vitamin $\mathrm{D}$ membrane receptor, acts directly on muscle cell membranes, resulting in enhanced calcium uptake within minutes, both through voltage-dependent calcium channels ${ }^{12}$ and calcium release-activated calcium channels. ${ }^{13}$ Finally, muscle strength appears to be influenced by the VDR genotype in muscle cells. In nonobese elderly women, a 23\% difference in quadriceps strength and a $7 \%$ difference in grip strength were found between the bb and BB genotype of the VDR. ${ }^{14}$

Osteoporosis in elderly patients of both sexes is characterized by uncoupled bone remodeling. This uncoupling is induced by sex hormone deficiencies, by the so-called somatopause (growth hormone or insulin-like growth factor deficiency), by vitamin D deficiency, and, importantly, by reduced synthesis of D-hormone in the kidneys ${ }^{15}$ and bones ( $1 \alpha$-hydroxylase deficiency). ${ }^{16}$ It is also induced by lack of receptors or receptor affinity for $\mathrm{D}$ hormone in target organs ${ }^{17}$ (gastrointestinal tract, bones, and parathyroid gland). ${ }^{18}$ Inadequate $1,25(\mathrm{OH})_{2} \mathrm{D}_{3}$ levels will lead to lower intestinal calcium absorption, so more calcium will be mobilized from the skeleton, resulting in increased bone resorption. Additionally, insufficient D hormone levels result in limited synthesis of bone matrix proteins that are released by osteoblasts. This limited synthesis of bone matrix proteins as well as the limited regulation of cytokines which are important for bone turnover exert a negative influence on bone mass and quality. ${ }^{19}$ Consequently, treatment with $1,25(\mathrm{OH})_{2} \mathrm{D}_{3}$ may be beneficial for osteoporotic patients, especially in the elderly population. 


\section{VDR polymorphism and response to calcitriol}

The biological responses to vitamin $\mathrm{D}$ are mediated by the VDR, which is a DNA-binding transcription factor. VDR generates an active signal transduction complex consisting of a heterodimer of the $1 \alpha, 25(\mathrm{OH})_{2} \mathrm{D}_{3}$-liganded VDR and an unoccupied retinoid $\mathrm{X}$ receptor. This complex is able to recognize vitamin D-responsive elements in the DNA sequence of genes regulated by vitamin D. ${ }^{20}$ By recruiting complexes of either coactivators or corepressors, activated VDR modulates the transcription of gene encoding proteins that promulgate the traditional genomic functions of vitamin $\mathrm{D}$, for example, signaling intestinal calcium and phosphate absorption to affect skeletal and calcium homeostasis. The VDR gene located on chromosome 12 cen-q12 contains 11 exons, and spans approximately 75 kilobases of genomic DNA. ${ }^{21}$ It has been suggested that it is one of the candidate genes for genetic control of bone mass. Allelic variants of the $V D R$ gene, recognized by ApaI (allele A/a C-A), BsmI (allele B/b G-A), FokI (allele F/f C-T), and TaqI (allele T/t T-C) restriction endonucleases, have been associated with bone mineral density (BMD) in many studies as well as with bone loss in elderly subjects. ${ }^{22}$ There is racial diversity in the distribution of $V D R$ gene polymorphism. In a study carried out by Zhang et al on $V D R$ gene diversity in the People's Republic of China ${ }^{23}$ that involved 426 postmenopausal women, data on the respective prevalence of bb, $\mathrm{Bb}$, and BB genotypes in women of the following ethnicities was reported: Han $(90.5 \%, 9.5 \%$, and $0 \%)$, Kazak (38.1\%, 55.56\%, and 6.35\%), Uygur (69.67\%, 26.23\%, and $4.1 \%$ ), and Mongolian (50\%, 45.54\%, and 4.46\%). This uneven distribution may reflect either recruitment bias or survival bias. A study of 145 elderly men ${ }^{24}$ evaluated the effects of the VDR BsmI gene on 1,25-dihydroxy vitamin $\mathrm{D}_{3}$ levels. The authors found that bb genotype individuals had low vitamin D3 levels in comparison with $\mathrm{BB}$ and $\mathrm{Bb}$ genotype individuals, although the results did not reach statistical significance. Studies of the effects of $V D R$ polymorphisms with respect to vitamin $\mathrm{D}$ intake or treatment are limited. Morrison et $\mathrm{al}^{25}$ conducted a study in 333 postmenopausal women from New Zealand who were given calcitriol $0.25 \mu \mathrm{g}$ /day plus calcium $1 \mathrm{~g}$ /day versus only calcium $1 \mathrm{~g} /$ day. This study showed significant interactions between the main effects of treatment and genotype ( $P=0.027, P=0.029$, and $P=0.016$, respectively, for the interaction term for models with ApaI, BsmI, and $T a q I)$. After 3 years, they found that the fracture incidence had decreased for the aaTT genotype and that the response to calcitriol was better for the Aatt genotype. Data on the relationship between $V D R$ polymorphisms and response to calcitriol treatment in elderly osteoporotic patients is still valid in the People's Republic of China.

\section{Effect of calcitriol on BMD}

We searched PubMed, EMBASE, and WanFang (http://www. wanfangdata.com.cn, a Chinese database) with article type restricted to clinical trials and publication time restricted to October 1, 2013 or earlier, using the following keywords: "calcitriol", "active vitamin D", "1,25(OH) $)_{2}$-vitamin D", "China", "Chinese", and "osteoporosis". Studies were included for review if the following conditions were met: they were randomized controlled trials; participants were patients with osteoporosis or bone loss; intervention consisted of use of calcitriol in the trial group and placebo or calcium in the control group; BMD as measured by dual-energy $\mathrm{X}$-ray absorptiometry at the lumbar spine and femoral neck were collected as the primary outcome; and bone turnover markers were the secondary outcome. We excluded trials that enrolled participants with coexisting medical conditions (eg, diabetes). Statistical analyses were performed in Review Manager 5.2 (RevMan, version 5.2; The Cochrane Collaboration, Copenhagen, Denmark).

Initially, 468 relevant trials were identified. Following a preliminary review, 437 papers were excluded because of duplication or irrelevance. The remaining 31 trials were closely reviewed. Among them, 25 articles were excluded for the following reasons: outcome of interest not described $(n=12)$, improper study design $(n=10)$ and participants had coexisting medical conditions $(n=3)$. As a result, there were six trials included in the current metaanalysis (Figure 1).

The characteristics of the included studies are summarized in Table 1. All were randomized controlled trials that involved elderly males or females (mean age ranged from 56.3 years to 70.4 years) with bone loss. Subjects were randomly divided into calcitriol groups and control groups, receiving $0.25 \mu \mathrm{g} /$ day calcitriol plus one Caltrate D $(600 \mathrm{mg}$ of calcium and 125 IU of vitamin D; Pfizer Consumer Healthcare Company, Madison, NJ, USA) tablet daily, and one Caltrate D or placebo tablet daily, respectively. At 12 or 24 months, efficacy was mostly determined by BMD, bone turnover markers, muscle strength, and balance.

The BMD measurements for the six studies before and after treatment are shown in Tables 2 and 3. Combining available data at 12 months, ${ }^{26-30}$ different BMD changes between control and trial groups were found (Figure 2) in spite of 


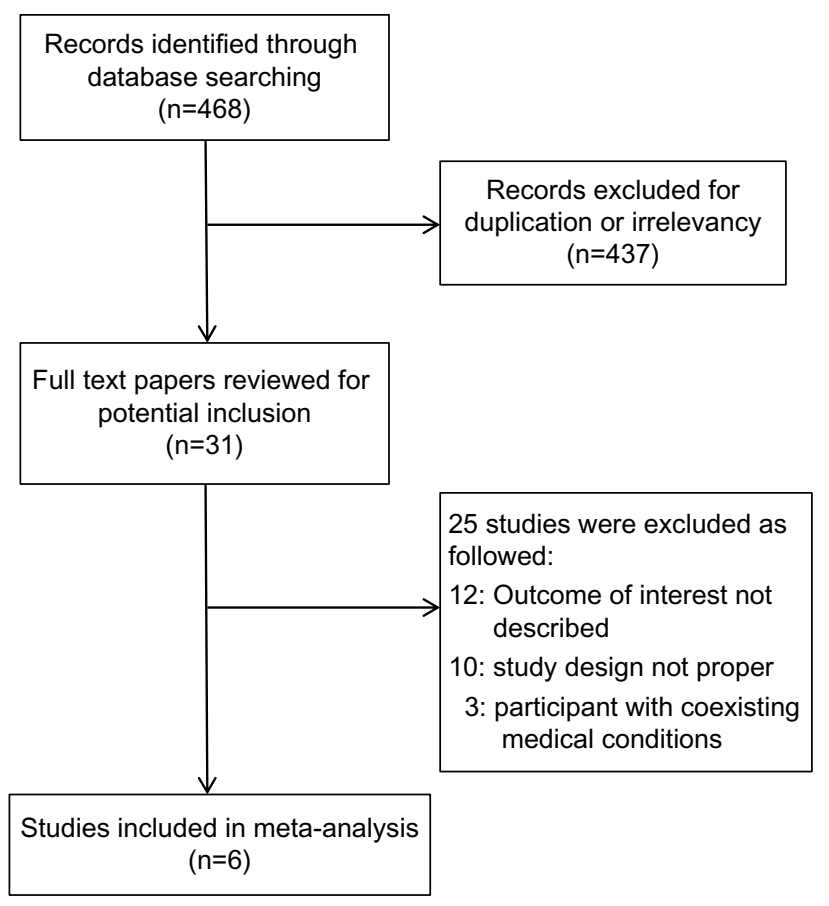

Figure I Diagram of literature search and selection.

heterogeneity. In the control groups, the BMD change was not significant and tended to be negative, while in the trial groups, BMD increased significantly. Available data for absolute BMD change (Figure 3) also points to significant preservation of lumbar spine and femoral neck BMD in the calcitriol groups. Some of these studies ${ }^{26,27}$ recorded significantly higher percentage changes at the lumbar spine from baseline compared with control groups after adjusting for baseline difference. BMD change at the femoral neck ranged from being not significant ${ }^{26,28}$ to significant. ${ }^{27,29}$ Thus, calcitriol may have a beneficial effect on BMD, especially at the lumbar spine, during 12 months of treatment. In one of the reviewed studies, which had a duration of 24 months and enrolled 300 post-menopausal women between the ages of 55 and 75 years, after 24 months of treatment with calcitriol $0.25 \mu \mathrm{g} / \mathrm{day}$ and one Caltrate D tablet daily, BMD at the lumbar spine, trochanter, and femoral neck all decreased slightly (from $0.970 \pm 0.184 \mathrm{~g} / \mathrm{cm}^{2}$ to $0.968 \pm 0.186 \mathrm{~g} / \mathrm{cm}^{2}$, from $0.657 \pm 0.106 \mathrm{~g} / \mathrm{cm}^{2}$ to $0.644 \pm 0.108$ $\mathrm{g} / \mathrm{cm}^{2}$ and from $0.724 \pm 0.083 \mathrm{~g} / \mathrm{cm}^{2}$ to $0.722 \pm 0.102 \mathrm{~g} / \mathrm{cm}^{2}$, respectively). We also noticed that in some studies ${ }^{31-33}$ that compared the efficacy of calcitriol monotherapy with calcitriol therapy combined with other antiosteoporotic agents, some calcitriol monotherapy groups showed no significant changes in BMD after treatment. These data suggest that using calcitriol monotherapy to treat osteoporosis in elderly patients may not provide sufficient benefits, especially as a long-term treatment.

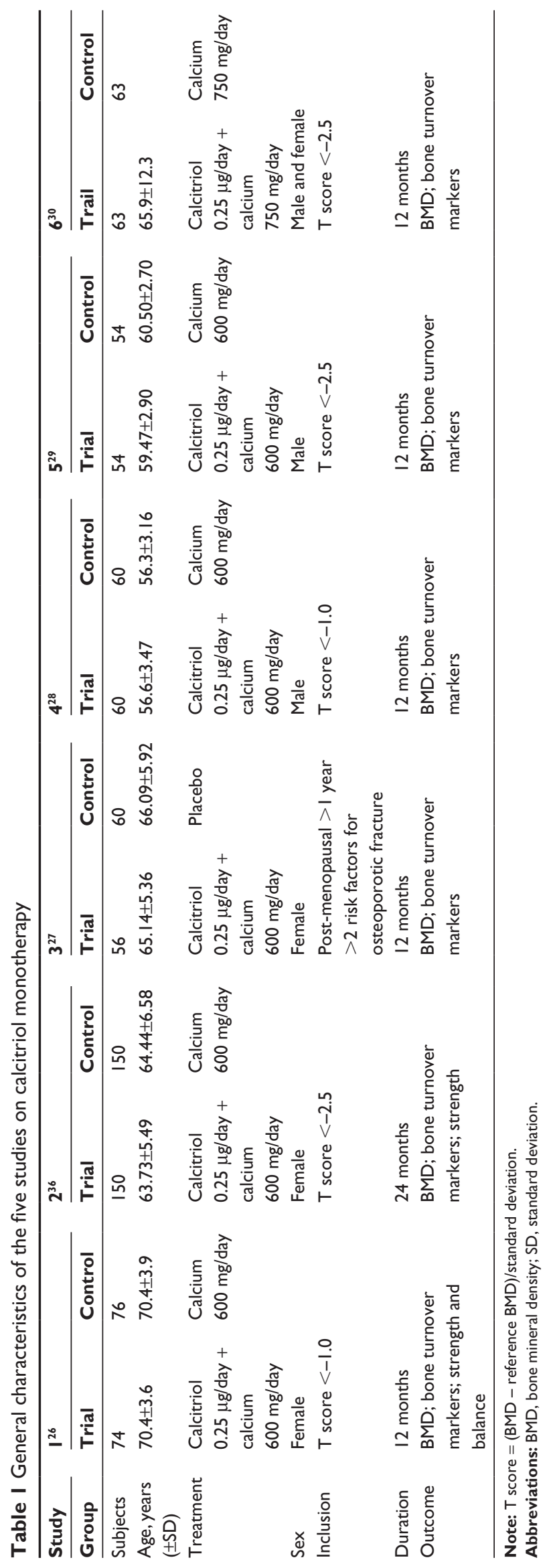


Table 2 BMD changes at L2-4 in the five studies of calcitriol monotherapy

\begin{tabular}{|c|c|c|c|c|c|}
\hline Study & Patients (n) & $\begin{array}{l}\text { Pretreatment } \\
\left(\mathrm{g} / \mathrm{cm}^{2}\right)\end{array}$ & $\begin{array}{l}\text { I } 2 \text { or } 24 \text { months } \\
\left(\mathrm{g} / \mathrm{cm}^{2}\right)\end{array}$ & $\begin{array}{l}\text { Percentage } \\
\text { change }\end{array}$ & $\begin{array}{l}\text { Absolute } \\
\text { change }\end{array}$ \\
\hline \multicolumn{6}{|l|}{ Xia et $\mathrm{al}^{26}$} \\
\hline Caltrate D & 72 & $0.930 \pm 0.126$ & $0.935 \pm 0.137^{b}$ & $0.83 \pm 3.88$ & $0.008 \pm 0.036$ \\
\hline Calcitriol + Caltrate D & 70 & $0.916 \pm 0.132$ & $0.945 \pm 0.130^{c, f}$ & $2.84 \pm 4.04$ & $0.025 \pm 0.034$ \\
\hline \multicolumn{6}{|l|}{ He et $\mathrm{al}^{36}$} \\
\hline Caltrate D & 150 & $0.928 \pm 0.106$ & $0.933 \pm 0.121$ & & \\
\hline Calcitriol + Caltrate D & 150 & $0.970 \pm 0.184$ & $0.968 \pm 0.186$ & & \\
\hline \multicolumn{6}{|l|}{ Xie et $\mathrm{a}^{27}$} \\
\hline Control & 51 & $0.902 \pm 0.155$ & $0.902 \pm 0.154$ & $0.19 \pm 4.05$ & \\
\hline Calcitriol + Caltrate D & 47 & $0.907 \pm 0.130$ & $0.959 \pm\left. 0.13\right|^{c, f}$ & $5.94 \pm 4.62$ & \\
\hline \multicolumn{6}{|l|}{$\mathrm{He}$ et $\mathrm{a}^{28}$} \\
\hline Caltrate D & 58 & $0.76 \pm 0.12$ & $0.7 I \pm 0.13$ & & \\
\hline Calcitriol + Caltrate D & 57 & $0.75 \pm 0.14$ & $0.82 \pm 0.18^{b, f}$ & & \\
\hline \multicolumn{6}{|l|}{ Zhu et $\mathrm{al}^{29}$} \\
\hline Caltrate D & 49 & $0.75 \pm 0.02$ & $0.74 \pm 0.02$ & & $-0.01 \pm 0.09$ \\
\hline Calcitriol + Caltrate D & 52 & $0.76 \pm 0.03$ & $0.79 \pm 0.04^{\mathrm{b}, \mathrm{f}}$ & & $0.03 \pm 0.06$ \\
\hline \multicolumn{6}{|l|}{ Yang et $\mathrm{al}^{30}$} \\
\hline Caltrate D & 63 & $0.74 \pm 0.03$ & $0.75 \pm 0.04$ & & $0.01 \pm 0.05$ \\
\hline Calcitriol + Caltrate D & 63 & $0.73 \pm 0.04$ & $0.84 \pm 0.05^{\mathrm{c}, \mathrm{f}}$ & & $0.11 \pm 0.17$ \\
\hline
\end{tabular}

Notes: 12 or 24 months denotes $12^{26-30}$ or $24^{36}$ months after treatment. Values are expressed as the mean \pm standard deviation. ${ }^{b} P<0.05$. ${ }^{c} P<0.01$ versus baseline by paired $t$-test. ${ }^{f} P<0.01$ compared between two groups by analysis of covariance adjusted for baseline BMD.

Abbreviation: BMD, bone mineral density.

\section{Effects of calcitriol in combination with other antiosteoporotic agents}

Studies have shown that calcitriol can be well tolerated in combination with many kinds of antiosteoporotic agents, including bisphosphonates, calcitonin, hormonal replacement therapy, selective estrogen receptor modulators, and traditional Chinese medicine. We searched PubMed, EMBASE, and WanFang for articles containing the keywords "China", "Chinese", and "osteoporosis", and abstracts including "calcitriol". Randomized controlled trials were included

Table 3 BMD changes at the femoral neck in five studies of calcitriol monotherapy

\begin{tabular}{|c|c|c|c|c|c|}
\hline Study & $\begin{array}{l}\text { Patients } \\
\text { (n) }\end{array}$ & $\begin{array}{l}\text { Pretreatment } \\
\left(\mathrm{g} / \mathrm{cm}^{2}\right)\end{array}$ & $\begin{array}{l}12 \text { or } 24 \text { months } \\
\left(\mathrm{g} / \mathrm{cm}^{2}\right)\end{array}$ & $\begin{array}{l}\text { Percentage } \\
\text { change }\end{array}$ & $\begin{array}{l}\text { Absolute } \\
\text { change }\end{array}$ \\
\hline \multicolumn{6}{|l|}{ Xia et $a^{26}$} \\
\hline Caltrate D & 72 & $0.73 I \pm 0.096$ & $0.730 \pm 0.095$ & $0.04 \pm 3.94$ & $0.000 \pm 0.029$ \\
\hline Calcitriol + Caltrate D & 70 & $0.688 \pm 0.094$ & $0.703 \pm 0.092^{c}$ & $2.0 I \pm 5.45$ & $0.012 \pm 0.037$ \\
\hline \multicolumn{6}{|l|}{ He et $\mathrm{al}^{36}$} \\
\hline Caltrate D & 150 & $0.753 \pm 0.090$ & $0.726 \pm 0.073$ & & \\
\hline Calcitriol + Caltrate D & 150 & $0.724 \pm 0.083$ & $0.722 \pm 0.102$ & & \\
\hline \multicolumn{6}{|l|}{ Xie et $\mathrm{a}^{27}$} \\
\hline Control & 51 & $0.693 \pm 0.100$ & $0.709 \pm 0.089$ & $-0.03 \pm 4.40$ & \\
\hline Calcitriol + Caltrate D & 47 & $0.695 \pm 0.105$ & $0.7|4 \pm 0.09|^{b}$ & $3.43 \pm 10.34$ & \\
\hline \multicolumn{6}{|l|}{ He et $\mathrm{al}^{28}$} \\
\hline Caltrate D & 58 & $0.56 \pm 0.10$ & $0.52 \pm 0.08$ & & \\
\hline Calcitriol + Caltrate D & 57 & $0.54 \pm 0.09$ & $0.59 \pm 0.13^{b, f}$ & & \\
\hline \multicolumn{6}{|l|}{ Zhu et $\mathrm{a}^{29}$} \\
\hline Caltrate D & 49 & $0.52 \pm 0.04$ & $0.5 I \pm 0.03$ & & $-0.01 \pm 0.12$ \\
\hline Calcitriol + Caltrate D & 52 & $0.52 \pm 0.03$ & $0.55 \pm 0.02^{\mathrm{b}, \mathrm{f}}$ & & $0.03 \pm 0.06$ \\
\hline \multicolumn{6}{|l|}{ Yang et $\mathrm{al}^{30}$} \\
\hline Caltrate D & 63 & $0.52 \pm 0.04$ & $0.53 \pm 0.02$ & & $0.01 \pm 0.05$ \\
\hline Calcitriol + Caltrate D & 63 & $0.5 I \pm 0.03$ & $0.59 \pm 0.04^{\mathrm{c}, f}$ & & $0.08 \pm 0.12$ \\
\hline
\end{tabular}

Notes: 12 or 24 months denotes $12^{26-30}$ or $24^{36}$ months after treatment. Values are expressed as the mean \pm standard deviation. ${ }^{b} P<0.05$. ${ }^{c} P<0.0$ I versus baseline by paired $t$-test. ${ }^{f} P<0.01$ compared between two groups by analysis of covariance adjusted for baseline BMD.

Abbreviation: BMD, bone mineral density. 
A L2-4 BMD change for caltrate D groups $\left(\mathrm{g} / \mathrm{cm}^{2}\right)$

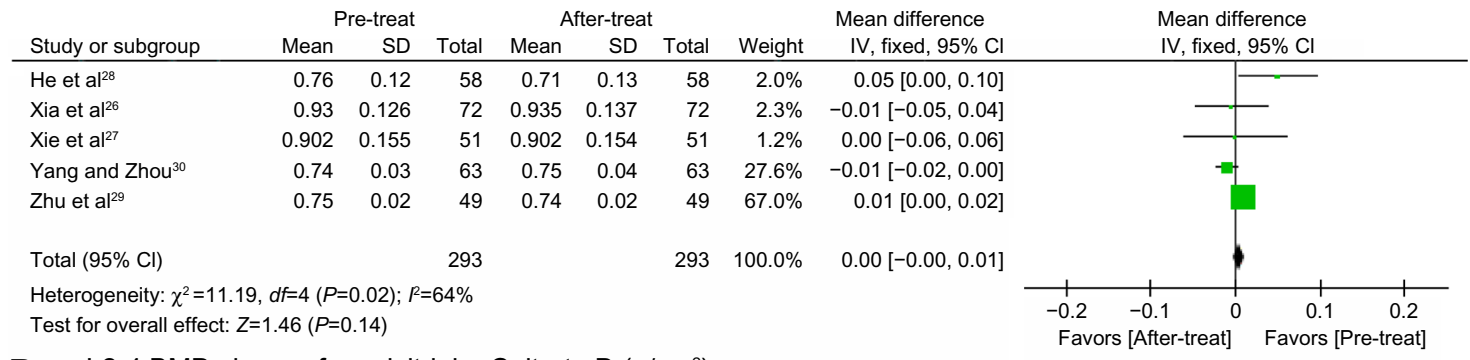

B L2-4 BMD change for calcitriol + Caltrate D $\left(\mathrm{g} / \mathrm{cm}^{2}\right)$

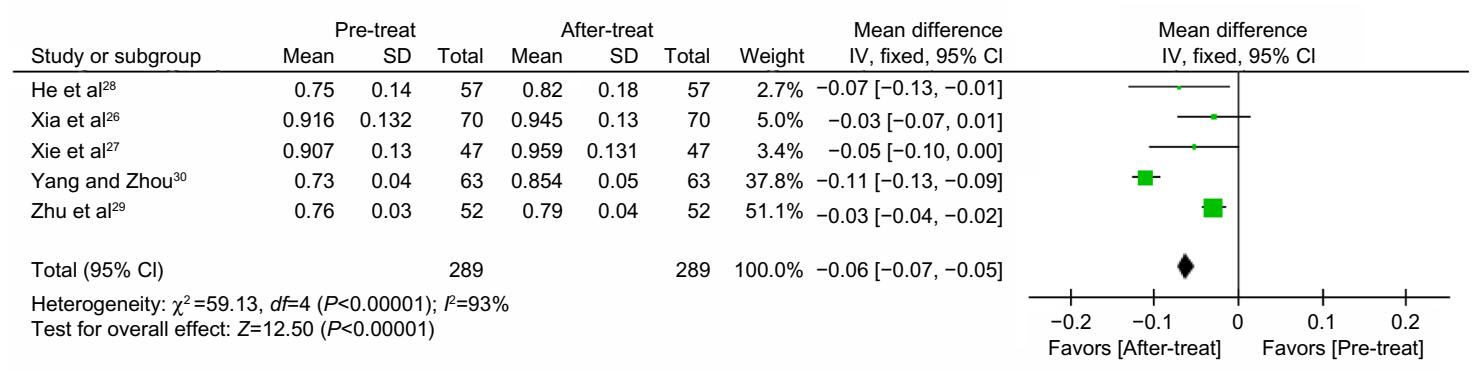

\section{Femoral neck BMD change for Caltrate D groups $\left(\mathrm{g} / \mathrm{cm}^{2}\right)$}

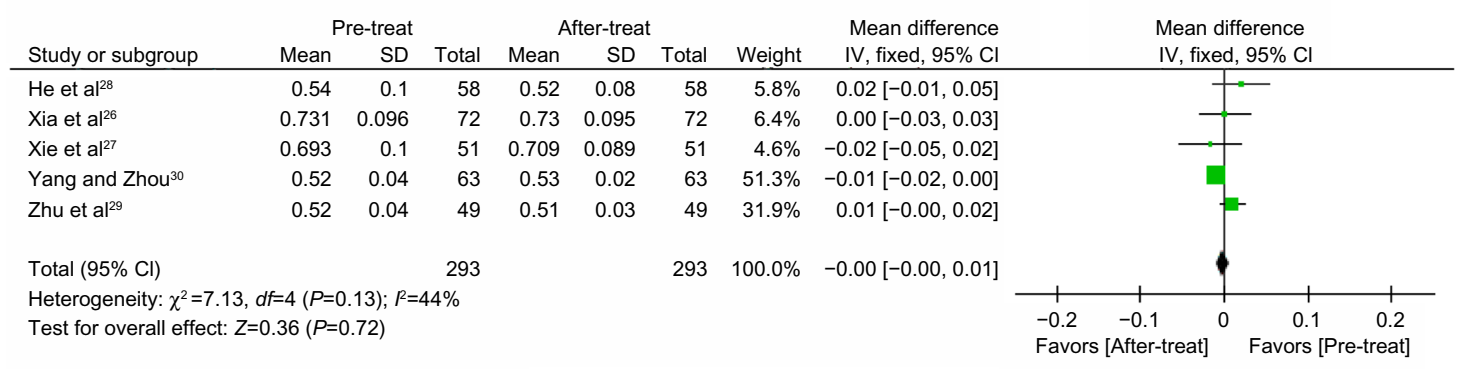

D Femoral neck BMD change for calcitriol + Caltrate D $\left(\mathrm{g} / \mathrm{cm}^{2}\right)$

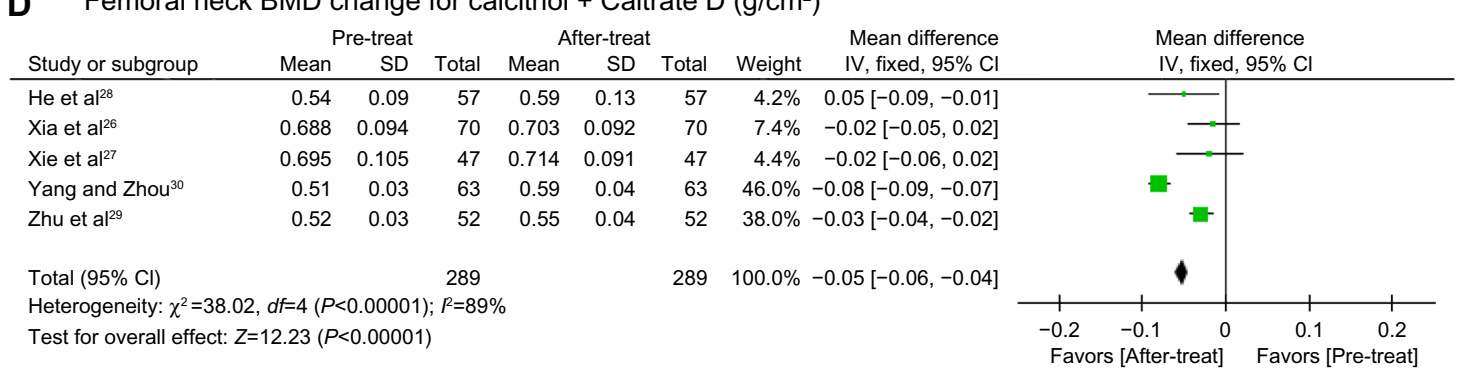

Figure 2 BMD change at L2-4 and the femoral neck. Pooled estimate for the BMD change after I2 months of treatment with Caltrate D at L2-4 (A), calcitriol + Caltrate D at L2-4 (B), Caltrate D at the femoral neck (C) and calcitriol + Caltrate D at the femoral neck (D).

Notes: Boxes denote estimated mean differences; bars show $95 \% \mathrm{Cls}$; diamond indicates pooled mean differences; and the width of the diamond indicates pooled Cls.

Abbreviations: L2-4, lumbar vertebrae 2-4; Cls, confidence intervals; BMD, bone mineral density; SD, standard deviation; pre-treat, pretreatment; after-treat, after treatment; IV, inverse variance.

if they met the following criteria: participants were patients with osteoporosis; the subject number was more than 100; the intervention consisted of calcitriol monotherapy and calcitriol therapy in combination with other antiosteoporotic agents; and outcomes included BMD change, bone fracture, bone pain, or bone turnover markers. The search strategy retrieved 151 unique citations. Of these, 119 were excluded following initial screening based on abstracts or titles. After full-text review, five of the 32 remaining studies met the inclusion criteria (Table 4). Of the five trials selected, three involved bisphosphonates, two involved calcitonin, and one involved hormonal replacement therapy.

Evidence presented by the trials suggested that combination therapy could decrease the incidence of bone fracture. Liu et $\mathrm{al}^{31}$ carried out a 3-month study on 345 patients with previous osteoporotic vertebral compression fractures; 192 subjects in the trial group received salmon calcitonin (50 IU/day for the first week, 50 IU every 2 days after the first week) and oral calcitriol capsules $(0.25 \mu \mathrm{g}$ calcitriol three times a day), while 153 subjects in the control group received 
A L2-4 BMD absolute change $\left(\mathrm{g} / \mathrm{cm}^{2}\right)$

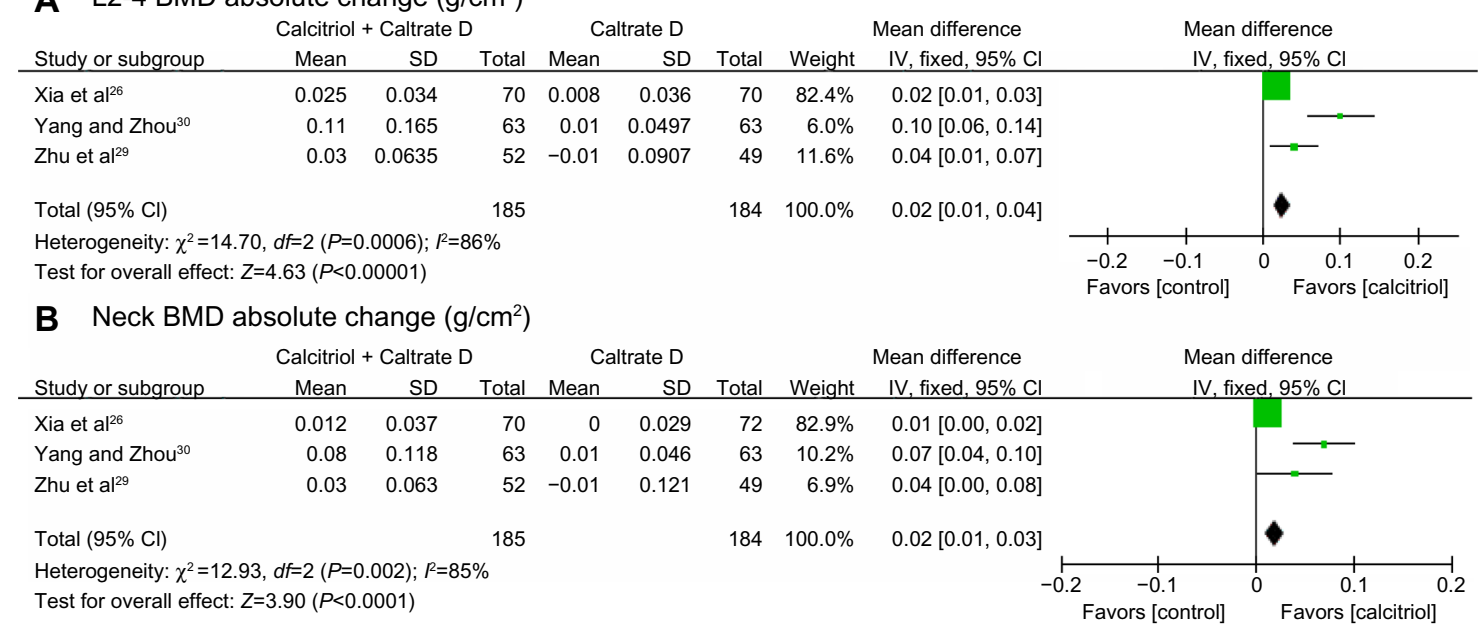

Figure 3 Absolute BMD change at L2-4 and the femoral neck. Pooled estimate for the difference in absolute BMD change after 12 months of treatment with Caltrate D or Caltrate D + calcitriol at L2-4 (A) and the femoral neck (B).

Notes: Boxes denote estimated mean differences; bars show $95 \%$ Cls; diamond indicates pooled mean differences; and the width of the diamond indicates pooled Cls. Abbreviations: L2-4, lumbar vertebral levels 2-4; Cls, confidence intervals; NECK, femoral neck; BMD, bone mineral density; SD, standard deviation; IV, inverse variance.

oral calcitriol capsules $(0.25 \mu \mathrm{g}$ calcitriol three times a day) only. The results indicated that salmon calcitonin and calcitriol combination therapy can decrease the incidence of subsequent fracture, which was $12 \%$ in the salmon trial group and $27.5 \%$ in the control group. An open study was carried out by Xuan et $\mathrm{al}^{32}$ in 567 women with postmenopausal osteoporosis who were given calcitriol $0.25 \mu \mathrm{g}$ /day alone and calcitriol $0.25 \mu \mathrm{g} /$ day in combination with zoledronic acid $5 \mathrm{mg} /$ year or tibolone $2.5 \mathrm{mg}$ /day (a hormone replacement drug). This study showed that combination therapy can reduce the risk of new vertebral fracture by $61.9 \%(4.3 \%$ in the zoledronic acid and calcitriol group versus $12.6 \%$ in the calcitriol group) and $48.4 \%$ (6.5\% in the tibolone and calcitriol group versus $12.6 \%$ in the calcitriol group) over a 2-year period.

Several studies have focused on improvement of bone pain following combination therapy. Wang ${ }^{33}$ conducted a 6-month study in 320 osteoporotic patients and showed that bone pain was significantly improved in the trial group (alendronate $70 \mathrm{mg} /$ week plus calcitriol $0.25 \mu \mathrm{g} /$ day) compared with the control group (calcitriol $0.25 \mu \mathrm{g} /$ day), with a verbal rating scale score for pain decreasing from $1.79 \pm 0.42$ to $0.92 \pm 0.18(P<0.05)$ in the trial group and from $1.82 \pm 0.38$ to $1.68 \pm 0.48$ in the control group. A randomized controlled trial reported by $\mathrm{Miao}^{34}$ also showed a more significant pain improvement percentage in the trial group (zoledronic acid $5 \mathrm{mg} /$ year, calcitriol $0.25 \mu \mathrm{g} /$ day) than in the control group (calcitriol $0.25 \mu \mathrm{g} /$ day).

All of the studies reviewed in this section showed that calcitriol in combination with other therapeutic bone agents resulted in significant preservation of BMD compared with control treatments (Table 5). The gains in BMD from combination therapy could be related to synergistic bonepreserving mechanisms such as simultaneously decreasing bone resorption and increasing bone formation. ${ }^{35}$ As a result, we can conclude that calcitriol in combination with other therapeutic bone agents may exert beneficial effects on reduction of fracture risk and bone pain as well as on increments of BMD in osteoporosis treatment.

\section{Effects of calcitriol on bone turnover markers}

Biomarkers measured included nonspecific biomarkers, such as alkaline phosphatase, as well as specific markers, such as bone-specific alkaline phosphatase and gamma-carboxyglutamic acid-containing protein for bone formation and tartrate-resistant acid phosphatase for bone resorption. Bone turnover data are summarized in Table 6. After treatment in calcitriol monotherapy trials, $\beta$ C-terminal telopeptide ${ }^{36}$ alkaline phosphatase, ${ }^{37}$ bone-specific alkaline phosphatase, ${ }^{28,29}$ and tartrate-resistant acid phosphatase ${ }^{28,29}$ were found to be significantly decreased in patients treated with calcitriol and increased in controls. Gamma-carboxyglutamic acidcontaining protein was increased in both the calcitriol and control groups, although the results were not significant. ${ }^{27}$ Of the five studies that focused on calcitriol in combination with other therapeutic bone agents, three reported significant changes in biomarkers such as bone-specific alkaline phosphatase, terminal C-telopeptide of collagen type I, and tartrate-resistant acid phosphatase that favored the calcitriol 


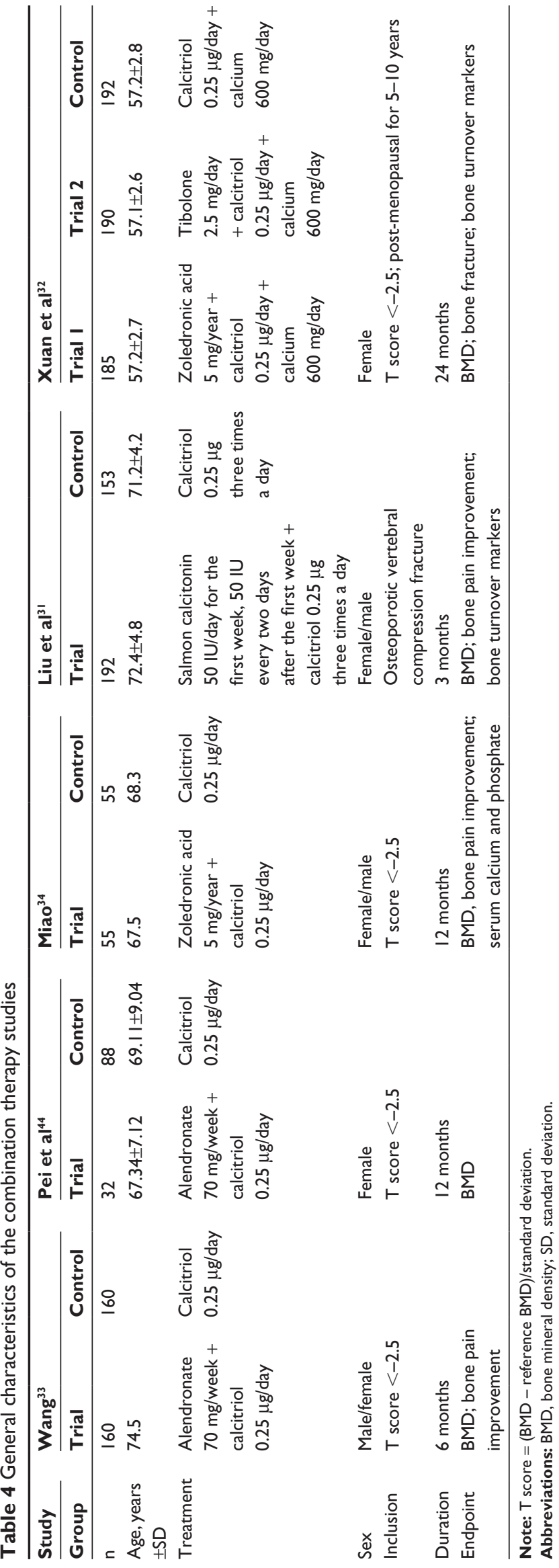

combination arm..$^{31,32,34}$ This evidence suggests that calcitriol may have suppressive effects on bone turnover.

\section{Effects of calcitriol on muscle strength and performance}

Only two studies concentrated on muscle strength and performance as a response to calcitriol treatment in Chinese patients with osteoporosis. Muscle strength was evaluated by the stand and maximal forward reach test and five times sit-to-stand test, as well as by testing grip strength. In the study conducted by Xia et al, ${ }^{26}$ left hand grip strength was significantly decreased in both groups following 6 months of treatment, although this change was not found after 12 months. At the same time, there were no significant changes in right hand grip strength observed in either group during the 12 months of treatment. The five times sit-to-stand test time decreased significantly from baseline in the control group but not in the calcitriol group, a difference the authors suggested may have been related to individual differences. The stand and maximal forward reach test time increased significantly in both groups. The other study found grip strength increased in both calcitriol and control groups following treatment. ${ }^{36}$ These data indicate that treatment with Caltrate $\mathrm{D}$ alone or a combination of calcitriol and Caltrate D may have beneficial effects on muscle strength in elderly Chinese women.

\section{Quality of life}

Quality of life scores for patients with osteoporosis are low, according to a study reported by Xu et al. ${ }^{37}$ Guo et $\mathrm{al}^{38}$ investigated the factors affecting quality of life in osteoporotic patients. Their subjects were 188 post-menopausal Chinese women aged 45-78 years with osteoporosis. Thirty-eight patients received no treatment on account of mild symptoms, and the remaining patients were randomly divided into three groups, ie, a bisphosphonate group, a calcium and calcitriol group, and a hormone replacement treatment group. Thirtythree factors, including treatment, general condition, health habits, and biological index were analyzed. Quality of life scores were measured before treatment and 3 and 12 months later using the Osteoporosis Quality of Life Scale developed by the Medical Outcome Evaluation for Gerontology research group. ${ }^{39}$ This scale has 75 items and spans dimensions including disease, physiology, psychology, sociology, and patient satisfaction. The results showed that all three treatments, ie, bisphosphonate, calcitriol, and hormonal replacement therapy, can improve quality of life, with bisphosphonate being the most effective. Other significant factors included milk intake, smoking, alcohol use, age, physical work, 
Table 5 BMD changes in the four studies with calcitriol therapy in combination with other antiosteoporotic agents

\begin{tabular}{|c|c|c|c|c|c|c|}
\hline \multirow[t]{2}{*}{ Study } & \multirow[t]{2}{*}{ Patient (n) } & \multirow{2}{*}{$\begin{array}{l}\text { Time } \\
\text { (months) }\end{array}$} & \multicolumn{2}{|c|}{ L2-4 BMD $\left(\mathrm{g} / \mathrm{cm}^{2}\right)$} & \multicolumn{2}{|c|}{ Femoral neck BMD $\left(\mathrm{g} / \mathrm{cm}^{2}\right)$} \\
\hline & & & Pretreatment & $\begin{array}{l}\text { After } \\
\text { treatment }\end{array}$ & Pretreatment & $\begin{array}{l}\text { After } \\
\text { treatment }\end{array}$ \\
\hline \multicolumn{7}{|l|}{ Wang ${ }^{33}$} \\
\hline Calcitriol & 160 & 6 & $0.82 I \pm 0.092$ & $0.830 \pm 0.086$ & $0.742 \pm 0.094$ & $0.752 \pm 0.104$ \\
\hline Calcitriol + alendronate & 160 & 6 & $0.819 \pm 0.117$ & $0.902 \pm 0.112^{\mathrm{b}, \mathrm{f}}$ & $0.740 \pm 0.098$ & $0.812 \pm 0.112^{\mathrm{b}, \mathrm{f}}$ \\
\hline \multicolumn{7}{|l|}{ Pei et $\mathrm{al}^{44}$} \\
\hline Calcitriol & 88 & 12 & $0.763 \pm 0.098$ & $0.742 \pm 0.095^{\mathrm{b}}$ & $0.637 \pm 0.073$ & $0.60 \mathrm{I} \pm 0.078^{\mathrm{b}}$ \\
\hline Calcitriol + alendronate & 32 & 12 & $0.729 \pm 0.122$ & $0.743 \pm 0.129^{\mathrm{b}, \mathrm{f}}$ & $0.599 \pm 0.086$ & $0.635 \pm 0.112^{\mathrm{b}, \mathrm{f}}$ \\
\hline \multicolumn{7}{|l|}{$\mathrm{Miao}^{34}$} \\
\hline Calcitriol & 55 & 12 & $0.723 \pm 0.176$ & $0.752 \pm 0.163^{b}$ & & \\
\hline Calcitriol + zoledronic acid & 55 & 1 & $0.725 \pm 0.201$ & $0.858 \pm 0.198^{\mathrm{c}, \mathrm{f}}$ & & \\
\hline \multicolumn{7}{|l|}{ Liu et $\mathrm{a}^{|3|}$} \\
\hline Calcitriol & 153 & 3 & $0.79 \pm 0.10$ & $0.81 \pm 0.12$ & & \\
\hline Calcitriol + calcitonin & 192 & 3 & $0.80 \pm 0.09$ & $0.88 \pm 0.1 I^{b, f}$ & & \\
\hline
\end{tabular}

Notes: Values are expressed as the mean \pm standard deviation. ${ }^{b} P<0.05$. ${ }^{c} P<0.01$ versus baseline by paired $t$-test. ${ }^{f} P<0.01$ compared between two groups by analysis of covariance adjusted for baseline BMD.

Abbreviations: BMD, bone mineral density; L2-4, lumbar vertebral levels 2-4.

and body mass index. Lian et $\mathrm{al}^{40}$ conducted a controlled clinical trial in 282 post-menopausal Chinese women with osteoporosis. The subjects were divided into three treatment groups, ie, calcitriol, calcitriol plus calcitonin, and calcitriol plus ibandronate. All patients were followed up for one year. The results indicated that calcitriol alone does not improve quality of life significantly unless combined with calcitonin or ibandronate, indicating that post-menopausal osteoporosis should be treated with combined therapy.

\section{Safety and tolerability}

Overdose of calcitriol may result in hypercalcemia, hypercalciuria, and hyperphosphatemia. Studies in Western countries have shown that hypercalcemia is present with calcitriol therapy in up to $40 \%$ of cases $^{35}$ and suggest that calcitriol, when used in higher doses, should not be combined with calcium supplementation. However, in all of the aforementioned Chinese studies, mild or no side effects of this type were found. Serum calcium and phosphorus concentrations were normal during the studies. No renal lithiasis or calcification was detected by ultrasound examination at the end of treatment. The small incidence of hypercalcemia may be due to the low doses used in Chinese patients, which is recommended at $0.25 \mu \mathrm{g}$ /day. This also suggests that low doses of calcitriol combined with calcium supplementation may be safe for use in the elderly Chinese population. At the same time, it is still necessary to monitor serum calcium and phosphorus levels, urinary calcium excretion, and parathyroid hormone for the purpose of adjusting the medication dosage..$^{41}$ In one study combining calcitriol and alendronate, ${ }^{42}$ serum calcium levels decreased in the calcitriol plus alendronate group after 6 months, while serum calcium levels were found to be elevated in the calcitriol group. Although not significant, this result suggests that coadministration of a bisphosphonate can attenuate the risk of hypercalcemia during treatment with calcitriol. This finding is also consistent with that of a previous experiment wherein higher doses of a vitamin D hormone analog were used in combination with alendronate without increased hypercalcemia. ${ }^{43}$ Calcitriol increases inorganic phosphate levels in serum, so caution is advised in patients with renal failure because of the danger of ectopic calcification. Serum phosphorus increased significantly in one of the studies ${ }^{36}$ $(P<0.05)$, but values remained within the normal range.

Patient withdrawal generally occurred due to gastrointestinal side effects, ${ }^{27-29,36,44}$ including abdominal distention and constipation, which were thought to be caused by Caltrate D. No significant differences in markers of hepatic and renal function were recorded. No deaths or life-threatening toxicities were reported in any of the studies reviewed. Overall, tolerability of calcitriol was good.

\section{Limitations of this review}

Some limitations were present in the Chinese studies that were reviewed here. First, although randomized, these studies were not double-blind. Investigators were blinded when interpreting dual-energy X-ray absorptiometry scans and bone turnover markers, but the subjects were not blinded because all the studies were open-label. Although this might not influence the main outcomes, such as BMD and bone turnover markers, it could have an influence on subjective assessments such as pain evaluations, thus introducing some amount of 


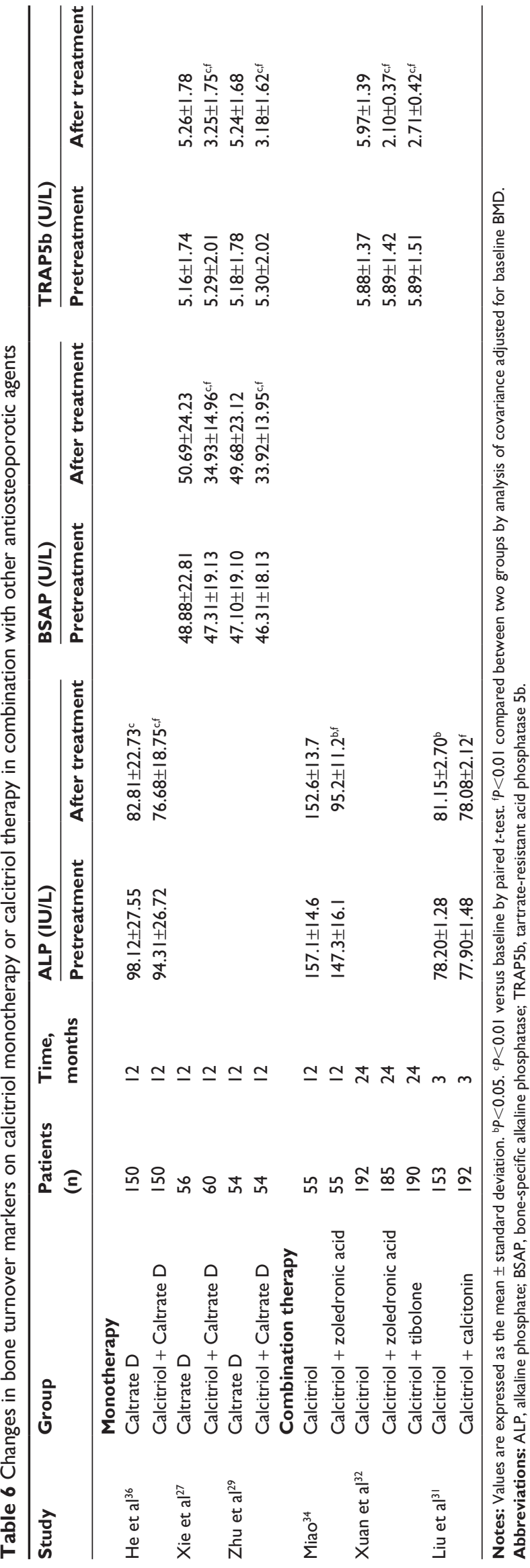

bias into the results. The second limitation was the small study sample sizes and the limited treatment periods. The longest duration among all of the studies was 24 months, and the results suggested that calcitriol monotherapy may be insufficient for long-term treatment of osteoporosis. Thus, the long-term effects and safety of calcitriol in elderly Chinese patients with osteoporosis still need to be explored. Finally, although some studies reported the incidence of fractures for calcitriol in combination with other antiosteoporotic agents, there were no studies that assessed fracture and fall incidence for calcitriol monotherapy, which is an important factor in evaluating the effectiveness of an antiosteoporotic drug. Above all, further double-blind studies with larger sample sizes as well as longer follow-up periods that assess bone fracture and fall incidence in addition to BMD and bone turnover markers are needed.

\section{Conclusion}

In conclusion, calcitriol, which is mediated by VDR, plays a role in many biological processes, in particular bone metabolism and muscle function. The evidence suggests that calcitriol may reduce or even reverse BMD loss, decrease bone turnover markers, and improve quality of life in elderly Chinese patients with osteoporosis in short-term treatment with mild or no side effects. However, the long-term effects of calcitriol monotherapy may be unsatisfactory, and this is an area in need of further research. Calcitriol can be well tolerated in combination with various other therapeutic bone agents, and these combinations can exert more significant beneficial effects on reduction of fracture risk, improvement of bone pain, and BMD increment in osteoporosis treatment compared with calcitriol monotherapy.

\section{Acknowledgment}

The authors thank Shanghai Roche Pharmaceuticals Limited for English language polishing assistance.

\section{Disclosure}

The authors report no conflicts of interest in this work.

\section{References}

1. [No authors listed]. [Editorial Board of Osteoporosis Prevention and Treatment (China White Paper)]. Chinese Journal of Health Management. 2009;3(3):148-154. Chinese.

2. Liang Y, Lu Z, Zhang N, Shen L. Evaluation of multi-dimensional outcomes of chronic diseases: a clinical example from China. Arch Gerontol Geriatr. 2011;52(3):106-109.

3. [No authors listed]. [The Chinese guideline for diagnosis and management of osteoporosis]. Chin J Osteoporosis and Bone Miner Res. 2011;4(1):2-17. Chinese. 
4. Drissi H, Pouliot A, Koolloos C, et al. 1,25-(OH)2-vitamin D3 suppresses the bone-related Runx2/Cbfa1 gene promoter. Exp Cell Res. 2002;274(2):323-333.

5. Nordin BE. Evolution of the calcium paradigm: the relation between vitamin D, serum calcium and calcium absorption. Nutrients. 2010;2(9): 997-1004.

6. Bikle D, Adams JS, Christakos S. Vitamin D: production, metabolism, mechanism of action and clinical requirements. In: Bikle D, Adams JS, Christakos S, editors. Primer on the Metabolic Bone Diseases and Disorders of Mineral Metabolism. 8th ed. Ames, IA, USA: Wiley-Blackwell; 2013.

7. Omdahl JL, Bobrovnikova EA, Choe S, Dwivedi PP, May BK. Overview of regulatory cytochrome P450 enzymes of the vitamin D pathway. Steroids. 2001;66(3-5):381-389.

8. Kaneko I, Segawa H, Furutani J, et al. Hypophosphatemia in vitamin D receptor null mice: effect of rescue diet on the developmental changes in renal Na+-dependent phosphate cotransporters. Pflugers Arch. 2011;461(1):77-90.

9. Birge SJ, Haddad JG. 25-hydroxycholecalciferol stimulation of muscle metabolism. J Clin Invest. 1975;56(5):1100-1107.

10. Janssen HC, Samson MM, Verhaar HJ. Vitamin D deficiency, muscle function, and falls in elderly people. Am J Clin Nutr. 2002;75(4): 611-615.

11. Boland R, de Boland AR, Marinissen MJ, Santillan G, Vazquez G, Zanello $\mathrm{S}$. Avian muscle cells as targets for the secosteroid hormone 1,25-dihydroxy-vitamin D3. Mol Cell Endocrinol. 1995;114(1-2):1-8.

12. De Boland AR, Boland RL. Non-genomic signal transduction pathway of vitamin D in muscle. Cell Signal. 1994;6(7):717-724.

13. Vazquez G, de Boland AR, Boland R. Stimulation of $\mathrm{Ca} 2+$ releaseactivated $\mathrm{Ca} 2+$ channels as a potential mechanism involved in nongenomic 1,25(OH)2-vitamin D3-induced Ca2+entry in skeletal muscle cells. Biochem Biophys Res Commun. 1997;239(2):562-565.

14. Geusens P, Vandevyver C, Vanhoof J, Cassiman JJ, Boonen S, Raus J. Quadriceps and grip strength are related to vitamin $D$ receptor genotype in elderly nonobese women. J Bone Miner Res. 1997;12(12): 2082-2088.

15. Silverberg SJ, Shane E, de la Cruz L, Segre GV, Clemens TL, Bilezikian JP. Abnormalities in parathyroid hormone secretion and 1,25-dihydroxyvitamin D3 formation in women with osteoporosis. N Engl J Med. 1989;320(5):277-281.

16. Lidor C, Sagiv P, Amdur B, et al. Decrease in bone levels of 1,25-dihydroxyvitamin D in women with subcapital fracture of the femur. Calcif Tissue Int. 1993;52(2):146-148.

17. Ebeling PR, Sandgren ME, DiMagno EP, Lane AW, DeLuca HF, Riggs BL. Evidence of an age-related decrease in intestinal responsiveness to vitamin D: relationship between serum 1,25-dihydroxyvitamin D3 and intestinal vitamin D receptor concentrations in normal women. $J$ Clin Endocrinol Metab. 1992;75(1):176-182.

18. Prince RL, Dick IM, Lemmon J, Randell D. The pathogenesis of agerelated osteoporotic fracture: effects of dietary calcium deprivation. J Clin Endocrinol Metab. 1997;82(1):260-264.

19. Schacht E. Rationale for treatment of involutional osteoporosis in women and for prevention and treatment of corticosteroid-induced osteoporosis with alfacalcidol. Calcif Tissue Int. 1999;65(4):317-327.

20. Haussler MR, Jurutka PW, Mizwicki M, Norman AW. Vitamin D receptor(VDR)-mediated actions of 1alpha,25(OH)(2)vitamin D(3): genomic and non-genomic mechanisms. Best Pract Res Clin Endocrinol Metab. 2011;25(4):543-559.

21. Crofts LA, Hancock MS, Morrison NA, Eisman JA. Multiple promoters direct the tissue-specific expression of novel N-terminal variant human vitamin D receptor gene transcripts. Proc Natl Acad Sci USA. 1998;95(18):10529-10534.

22. Kurabayashi T, Tomita M, Matsushita H, et al. Association of vitamin D and estrogen receptor gene polymorphism with the effect of hormone replacement therapy on bone mineral density in Japanese women. Am J Obstet Gynecol. 1999;180(5):1115-1120.

23. Zhang HH, Han ZT, Tao GS, et al. [Distribution of vitamin D receptor gene (Bsm I) polymorphisms in healthy postmenopausal women from Han, Uygur, Kazak, Mongoloid population in China]. Chinese Journal of Clinical Rehabilitation. 2006;10(20):160-162. Chinese.
24. Yide M, Jie L, Peiying H, et al. [Relationship of vitamin D receptor gene polymorphisms with bone turnover markers and 1,25-dihydroxy vitamin $\mathrm{D}_{3}$ in elderly men]. Chinese Journal of Clinical Rehabilitation. 2004;8(33):7469-7471. Chinese.

25. Morrison NA, George PM, Vaughan T, Tilyard MW, Frampton CM, Gilchrist NL. Vitamin D receptor genotypes influence the success of calcitriol therapy for recurrent vertebral fracture in osteoporosis. Pharmacogenet Genomics. 2005;15(2):127-135.

26. Xia WB, Zhang ZL, Wang HF, et al. The efficacy and safety of calcitriol and/or Caltrate D in elderly Chinese women with low bone mass. Acta Pharmacol Sin. 2009;30(3):372-378.

27. Xie AY, Liu TT, Sheng ZF, Liao EY, Zhang H. [The efficacy of combination therapy of calcium carbonate and calcitriol on osteoporosis for postmenopausal women]. China Pharmacist. 2011;(04):546-548. Chinese.

28. He B, He XM, Zhang WJ, Xu L, Wu W. [Research on the preventive effects of calcium and calcitriol on aged patients with osteopenia]. Journal of Sun Yat-Sen University (Medical Sciences). 2009;(S1): 193-195. Chinese.

29. Zhu YY, Wang Y, Chu L. [Effect of calcitriol and calcium on prevention and treatment of senile osteoporosis]. China Modern Doctor. 2012;50(7):66-67. Chinese.

30. Yang M, Zhou Y. [The study on the effectiveness of calcitriol in combination with calcium intake for senile osteoporosis]. Modern Journal of Integrated Traditional Chinese and Western Medicine. 2013;22(19):2098-2099. Chinese.

31. Liu L, Zhang DQ, Lin H. [Clinical observation of salmon calcitonin in the treatment of older osteoporotic vertebral compression fracture]. China Modern Doctor. 2013;51(12):71-73. Chinese.

32. Xuan M, Yang J, Li Y, et al. [Effects of zoledronic acid and tibolone on bone mineral density, indexes of bone metabolism, and the risk of fracture in patients with postmenopausal osteoporosis]. Chin J Endocrinol Metab. 2013;29(6):504-508. Chinese.

33. Wang LQ. [Study on the effectiveness of calcitriol in combination with alendronate for osteoporosis]. China Health Care and Nutrition. 2012;9(2):3399-3400. Chinese.

34. Miao DM. [Clinical trial on zolendronic acid therapy on osteoporosis]. China Baojianyingyang. 2012;12(2):599-600. Chinese.

35. Peppone LJ, Hebl S, Purnell JQ, et al. The efficacy of calcitriol therapy in the management of bone loss and fractures: a qualitative review. Osteoporos Int. 2010;21(7):1133-1149.

36. He QH, Zhou XM, Tang C, et al. [Clinical research of calcium and vitamin D3 on treating osteoporosis in middle-aged and old women]. Lab Med Clin. 2011;02:168-169, 171. Chinese.

37. Xu LL, You LM, Yan J. [Quality of life and related factors in patients with osteoporosis]. Journal of Nursing. 2010;17(14):13-18. Chinese.

38. Guo YF, Hu YF, Sun ZQ. [Multiple factor analysis of life quality of postmenopausal osteoporotic women]. Presented at the 2008 China Prevention and Treatment of Common Diseases for The Old Conference, Beijing, People's Republic of China, 2008, June 27-30.

39. Sun ZQ. [Clinical effect evaluation system for age-related diseases] China Science and Technology Achievements. 2007;(15):58. Chinese.

40. Lian F, Wang Y, Liu YY, et al. [Effects of different therapies on postmenopausal osteoporosis]. Journal of Sun Yat-Sen University (Medical Sciences). 2011;32(3):379-382. Chinese.

41. Cui CY, Wang HG. [Clinical application of calcitriol and adverse reactions]. Chinese Journal of Pharmaceutical Technology Economics and Management. 2008;2(9):69-72. Chinese.

42. Zhu SH, Ying LP. [The efficacy of combination therapy of alendronate and calcitriol on osteoporosis for postmenopausal women]. Modern Practical Medicine. 2011;23(4):441-442. Chinese.

43. Van Etten E, Branisteanu DD, Overbergh L, Bouillon R, Verstuyf A, Mathieu C. Combination of a 1,25-dihydroxyvitamin D3 analog and a bisphosphonate prevents experimental autoimmune encephalomyelitis and preserves bone. Bone. 2003;2(4):397-404.

44. Pei Y, Wang XR, Zhan ZW, et al. [Efficacy analysis of alendronate treatment on postmenopausal osteoporosis]. Chin J Osteoporosis. 2011;17(9):818-820. Chinese. 


\section{Publish your work in this journal}

Clinical Interventions in Aging is an international, peer-reviewed journal focusing on evidence-based reports on the value or lack thereof of treatments intended to prevent or delay the onset of maladaptive correlates of aging in human beings. This journal is indexed on PubMed Central, MedLine, the American Chemical Society's 'Chemical Abstracts Ser-

vice' (CAS), Scopus and the Elsevier Bibliographic databases. The manuscript management system is completely online and includes a very quick and fair peer-review system, which is all easy to use. Visit $\mathrm{http}: / / \mathrm{www}$.dovepress.com/testimonials.php to read real quotes from published authors.

Submit your manuscript here: http://www.dovepress.com/clinical-interventions-in-aging-journal 